\title{
Gravitational-Search Algorithm for Optimal Controllers Design of Doubly-fed Induction Generator
}

\author{
Saher Albatran', Muwaffaq I. Alomoush ${ }^{2}$, Ahmed M. Koran ${ }^{3}$ \\ ${ }^{1}$ Department of Electrical Engineering, Faculty of Engineering, Jordan University of Science and Technology, Jordan \\ ${ }^{2,3}$ Department of Electrical Power Engineering, Hijjawi Faculty for Engineering Technology, Yarmouk University, \\ Jordan
}

\begin{tabular}{l} 
Article Info \\
\hline Article history: \\
Received Oct 22, 2017 \\
Revised Dec 25, 2017 \\
Accepted Jan 7, 2018 \\
\hline
\end{tabular}

Keyword:

DFIG

Global optimization

Gravitational search algorithm

Optimal controllers

Wind energy

\begin{abstract}
Recently, the Gravitational-Search Algorithm (GSA) has been presented as a promising physics-inspired stochastic global optimization technique. It takes its derivation and features from laws of gravitation. This paper applies the GSA to design optimal controllers of a nonlinear system consisting of a doubly-fed induction generator (DFIG) driven by a wind turbine. Both the active and the reactive power are controlled and processed through a back-toback converter. The active power control loop consists of two cascaded proportional integral (PI) controllers. Another PI controller is used to set the q-component of the rotor voltage by compensating the generated reactive power. The GSA is used to simultaneously tune the parameters of the three PI controllers. A time-weighted absolute error $(I T A E)$ is used in the objective function to stabilize the system and increase its damping when subjected to different disturbances. Simulation results will demonstrate that the optimal GSA-based coordinated controllers can efficiently damp system oscillations under severe disturbances. Moreover, simulation results will show that the designed optimal controllers obtained using the GSA perform better than the optimal controllers obtained using two commonly used global optimization techniques, which are the Genetic Algorithm (GA) and Particle Swarm Optimization (PSO).
\end{abstract}

Copyright $\odot 2018$ Institute of Advanced Engineering and Science. All rights reserved.

\section{Corresponding Author:}

Saher Albatran,

Department of Electrical Engineering,

Faculty of Engineering,

Jordan University of Science and Technology, Irbid 221-10, Jordan.

Email: saalbatran@just.edu.jo

\section{INTRODUCTION}

Generated electric power from wind is growing at an increasing annual rate worldwide in the last decade as its cost has decreased considerably. Widespread use of wind power can largely reduce production costs, reduce carbon emissions, contribute to resolving global warming calls, and reduce the dependency on fossil fuels [1].

With the recent developments in power electronics technology, DFIG driven by a wind turbine [2] are becoming very popular and their worldwide market share is increasing quickly. DFIG has been widely used in grid-connected variable-speed constant-frequency wind energy conversion systems (WECS) due to their advantageous features such as higher efficiency, lower cost, wide-range operations, capability of producing reactive power, better energy capture, smoother operation, and flexible control. Therefore, with the increasing utilization of wind power in the interconnected power network, improving DFIG transient performance is becoming more significant in power system operations.

Tuning the parameters of a classical PI controller of a grid-connected DFIG-based WECS is complicated due to the high nonlinearity and complexity of the system. Optimization techniques are applied 
to determine the optimal parameters of a classical PI controller to enhance the performance of the WECS as its response change certainly with time. In [3] an adaptive fuzzy gain scheduling of PI controller is presented. The PI controller parameters are optimized online using an adaptive mechanism based on fuzzy logic. In [4] a non-dominated sorting GA alongside discrete Fourier transform is implemented to quantify the damping characteristics of the rotor-side current due to system disturbance. In recent years, different evolution algorithms [5], [6] including mean variance optimization (MVO) algorithm [7], GA [8], PSO [9-12], bacteria foraging optimization (PFO) algorithm [13], hybrid artificial neural network [14] and Gbest guided artificial bee colony algorithm [15], [16] are applied to optimize the parameters of the PI controller of the rotor side converter (RSC) and hence improve the damping of oscillatory modes in DFIG-based WECS. In [17] a PSO is presented to generate an on-off controller to ensure robustness and quality of the energy produced, wherein [18] a nonlinear rotor-side controller is designed based on $\mathrm{H}_{2}$ optimal control theory to demonstrate the synthesis of a maximum power point tracking (MPPT) algorithm. Authors in [19] presented an optimal tuning of the MPPT algorithm and the active disturbances rejection controller to reduce the impact of the change on the characteristics of DFIG-based WECS. In [20], authors presented a computational intelligence control method to optimize the performance of the back-to-back converter and to regulate the low voltage ride-through capability of DFIG-based WECS. In [21], the DFIG-based WECS small signal stability was analyzed and their impacts on the eigenvalues of a DFIG in a single machine infinite bus system was investigated. In [22], the states of DFIG are used to obtain the optimal feedback control with utilizing the rotor currents beside the rotor voltages. Fuzzy logic nonlinear controller and particle swarm optimization are used in [23] to handle the nonlinearities in DFIG and to optimize the controllers' gains. In [24], the authors optimized the performance of the grid side inverter (GSI) and RSC of grid-connected DFIG to minimize the tracking error based on discrete-time PSO inverse optimal controller. Differential geometry theory is used in [25] to control linearized DFIG-wind turbine model based on linear quadratic regulator. To enhance the DFIG during and after power system transients by optimizing the PI-controllers of the RSC, PSO is used in [26] and GA in [27]. In [28], the transients of the DFIG are optimized by minimizing the sum squared error deviation of the dc link voltage and the generator speed deviation.

GSA is one of the recent heuristic algorithms, which has been introduced as a physics-inspired method in 2009 [29], [30]. It takes derivation and the main characteristics of heuristics from "Newton's law of gravitation"; "Every particle in the universe attracts every other particle with a force that is directly proportional to the product of their masses and inversely proportional to the square of the distance between them" [31]. The GSA updates gravitational and inertia masses with the help of heavy masses and finds the optimum [29-31]. In the last few years, GSA has been successfully applied to solve world engineering optimization problems and demonstrate high quality performance in solving these problems [32-35].

In this paper, GSA is used to design optimal controllers for improving transient response of a nonlinear DFIG-based WECS. The optimal controllers are tested on different common types of disturbances. The results are compared to the results obtained using the two well-recognized global optimization algorithms, which are GA and PSO, to show the effectiveness of using GSA to attain a global optimal solution of the design problem under study.

\section{MODEL OF THE DFIG-BASED WECS}

Figure 1 depicts a grid-connected DFIG-based WECS. The system shown includes a wind turbine, an induction generator, a back-to-back converter (RSC and GSI) [36], and the utility-grid. The ac/dc and the dc/ac conversions are used to control the bidirectional power delivered from/to the rotor circuit and to/from the grid, respectively. The dynamic electrical and mechanical equations are summarized below.

The induction generator considered in this paper is a wound rotor induction machine. If the magnetic branch is assumed linear, the dynamic modeling of DFIG in arbitrary reference frame can be written as seen from the stator side as follows:

$$
\begin{aligned}
& v_{q s}=r_{s} i_{q s}+\omega \lambda_{d s}+p \lambda_{q s} \\
& v_{d s}=r_{s} i_{d s}-\omega \lambda_{q s}+p \lambda_{d s} \\
& v_{q r}^{\prime}=r^{\prime} r^{i^{\prime}} q r^{+}+\left(\omega-\omega_{r}\right) \lambda^{\prime} d r^{+p \lambda^{\prime}} q r \\
& v_{d r}^{\prime}=r^{\prime}{ }^{i^{\prime}}{ }_{d r}-\left(\omega-\omega_{r}\right) \lambda^{\prime}{ }_{q r}+p \lambda^{\prime} d r
\end{aligned}
$$




$$
\lambda_{q s}=L_{l s} i_{q s}+M\left(i_{q s}+i^{\prime} q r\right)
$$

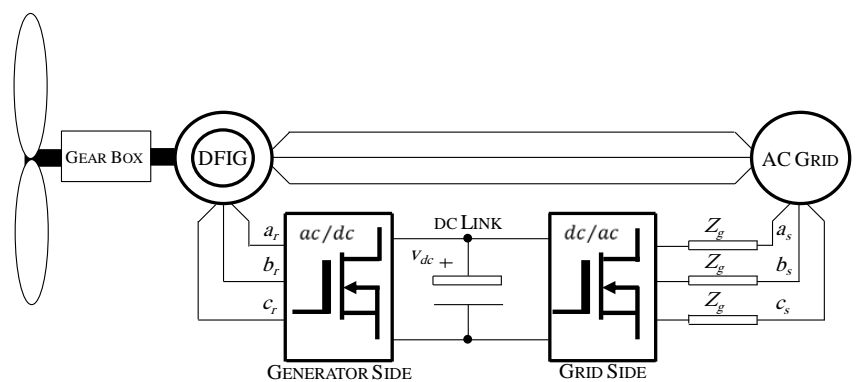

Figure 1. General configuration of grid-connected DFIG-based WECS

$$
\begin{aligned}
& \lambda_{d s}=L_{l s} i_{d s}+M\left(i_{d s}+i_{d r}^{\prime}\right) \\
& \lambda_{q r}^{\prime}=L^{\prime} l r{ }^{i^{\prime}}{ }_{q r}+M\left(i_{q s}+i^{\prime} q r\right) \\
& \lambda_{d r}^{\prime}=L^{\prime} l r{ }^{i^{\prime}} d r+M\left(i_{d s}+i_{d r}^{\prime}\right)
\end{aligned}
$$

where $v_{q s}, v_{d s}, i_{q s}, i_{d s}, \lambda_{q s}$ and $\lambda_{d s}$ are the stator voltages, currents, and flux linkages in qd-reference frame, respectively. $v_{q r}^{\prime}, v_{d r}^{\prime}, i_{q r}^{\prime}, i_{d r}^{\prime}, \lambda_{q r}^{\prime}$ and $\lambda_{d r}^{\prime}$ are the rotor voltages, currents, and flux linkages in qd reference frame, respectively. $\omega$ is the arbitrary angular speed, $\omega_{r}$ is the electrical angular speed of the rotor, ${ }_{p}$ is the derivative operator, $r_{S}$ is the stator windings resistance, $r^{\prime} r$ is the rotor windings resistance, $M=3 / 2 L_{m s}, L_{m s}$ is the stator magnetizing inductance, $L_{l r}^{\prime}$ is the rotor leakage inductance, and $L_{l s}$ is the stator leakage inductance.

If $P$ indicates number of poles, the electromechanical developed torque $T_{d}$ can be expressed as:

$$
T_{d}=\frac{3}{2} \frac{P}{2}\left(\lambda_{d s} i_{q s}-\lambda_{q s^{i}}{ }_{d s}\right)
$$

The dynamics of the mechanical shaft can be expressed based on the torque applied on the shaft $T_{\text {sh }}$ from both the generator end and the turbine end as follow:

$$
T_{s h}=T_{\tau}+J_{\tau} \frac{d \omega_{\tau}}{d t}=T_{m}+J_{m} \frac{d \omega_{m}}{d t}
$$

where $T_{\tau}$ is the applied mechanical torque at the turbine side, $T_{m}$ is the electrical torque seen at the generator side, $J_{\tau}$ and $J_{m}$ are the inertia of the turbine and the generator, respectively, and $\omega_{\tau}$ and $\omega_{m}$ are the angular speed of the turbine and the generator, respectively. The existence of the speed difference on the shaft ends and the compliance coefficient of the shaft $K_{s h}$ can determine the shaft-torsion $\left(\theta_{g}-\theta_{\tau}\right)$ as in (11):

$$
\theta_{g}-\theta_{\tau}=\int\left(\omega_{m}-\omega_{\tau}\right) \cdot d t=\frac{T_{S h}}{K_{s h}}
$$


As shown in Figure 2, both the active and the reactive power are controlled through the back-toback converter. The active power control loop, which sets the d-component of the rotor voltage $v_{d r}^{\prime}$, consists of two cascaded PI-controllers; the first one is used to regulate the rotor speed and to set the reference active power to the second PI-controller which is used to compensate the generated active power $\boldsymbol{P}_{\boldsymbol{S}}$. Another PI controller is used to set the q-component $v_{q r}^{\prime}$ by compensating the generated reactive power $Q_{S}$. The mathematical description of the PI controllers is given by:

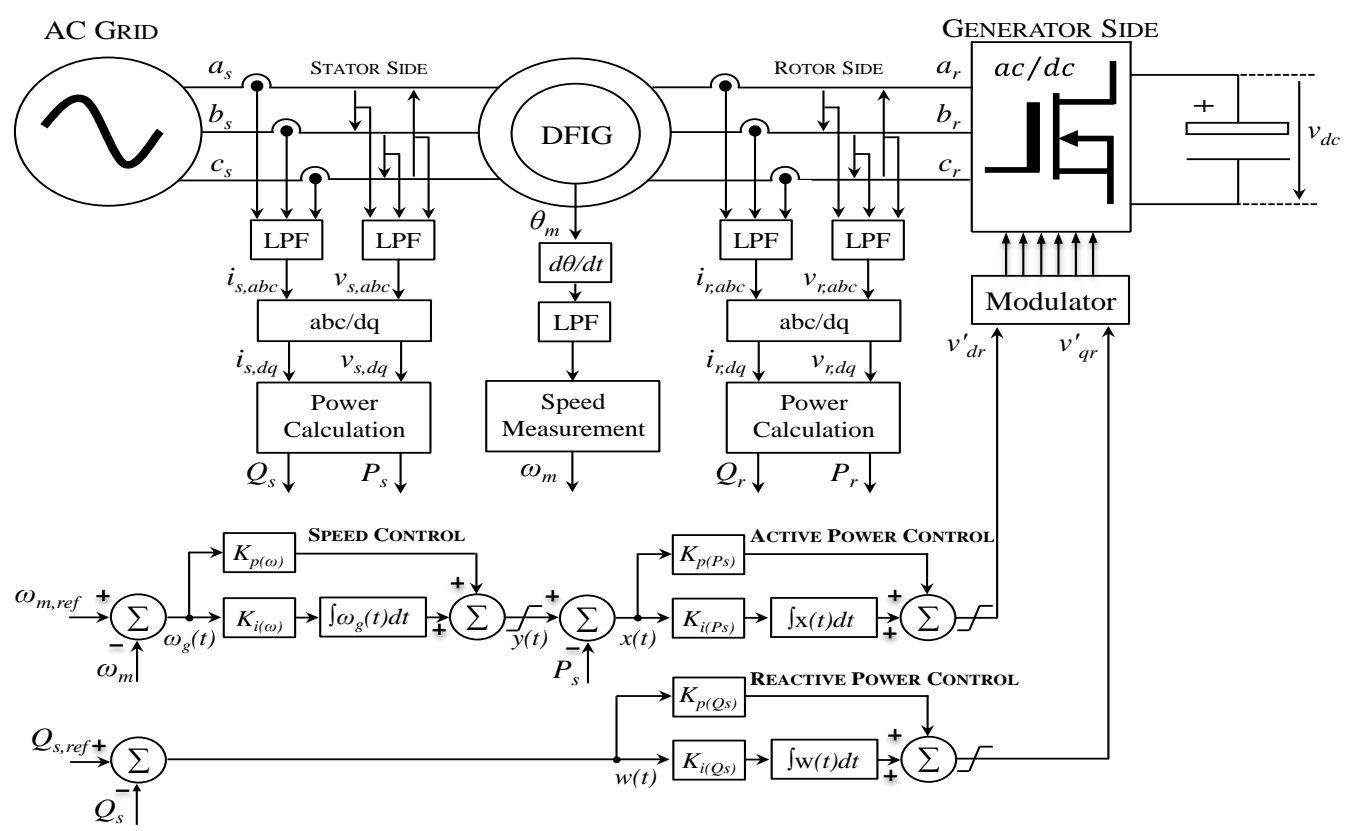

Figure 2. Block diagram of the grid-connected DFIG-based WECS with its associated control system

$$
\begin{aligned}
& v^{\prime} d r(t)=K_{p P_{S}} x(t)+K_{i} P_{S} \int_{0}^{t} x(\sigma) d \sigma \\
& y(t)=K_{p \omega} \omega_{\mathrm{g}}(t)+K_{i \omega} \int_{0}^{t} \omega_{g}(\sigma) d \sigma \\
& v_{q r}^{\prime}(t)=K_{p Q_{S}} \mathrm{w}(t)+K_{i} Q_{S} \int_{O}^{t} w(\sigma) d \sigma
\end{aligned}
$$

The constants $K_{p \omega}, K_{i \omega}, K_{p P_{S}}, K_{i P_{S}}, K_{p Q_{S}}, K_{i Q_{S}}$ are the proportional gains and integral gains of the PI controller as shown in Figure 2. Each gain of them is responsible for doing a specific task made on the input deviation signal; proportional gains $\left(K_{p \omega}, K_{p P_{S}}, K_{p Q_{S}}\right)$ are concerned with system stability; the integral gains ( $K_{i \omega}, K_{i P_{S}}, K_{i Q_{S}}$ ) are used of the steady-state error. In order to restrict the level of output of the PI controlled speed fluctuation during transient conditions, limits are imposed as shown in Figure 2.

The parameters of the control system to be optimally tuned are the six PI controller constants $\left(K_{p \omega}, K_{i \omega}, K_{p P_{S}}, K_{p Q_{S}}, K_{i Q_{S}}\right)$. In control system analysis and design, performance indices are used to assess a system behavior. This behavior is judged to be optimal when the performance induces reach minimum values and all system constraints are satisfied. In this paper, the integral of the time-weighted absolute error (ITAE) measure is used, which is given as in (15). 


$$
\text { ITAE }=\int_{0}^{t_{S}} t|e(t)| d t
$$

where $t_{S}$ is the simulation time, and $e(t)$ is the error signal which represent the difference between a reference value and a measured variable. The error signal is selected as the speed error signal $\left(e(t)=\omega_{m, r e f}-\omega_{m}\right)$.

The optimal values of controller gains are optimally tuned solving the following generalized optimization problem:

$$
\begin{aligned}
& \text { Minimize ITAE }\left(K_{p \omega}, K_{i \omega}, K_{p Q_{S}}, K_{i Q_{S}}, K_{p P_{S}}, K_{i P_{S}}\right) \\
& \text { Subject to }_{K^{\min } \leq K_{p \omega} \leq K_{p \omega}^{\max }} \\
& K^{\min } \leq K_{i \omega} \leq K_{i \omega}^{\max } \\
& K_{i \omega}^{\min } \leq K_{p Q_{S}} \leq K_{p Q_{S}}^{\max } \\
& Q_{S} \\
& K_{i Q_{S}}^{\min } \leq K_{i Q_{S}} \leq K_{i Q_{S}}^{\max } \\
& K_{p P_{S}}^{\min } \leq K_{p P_{S}} \leq K_{p P_{S}}^{\max } \\
& K_{i P_{S}}^{\min } \leq K_{i P_{S}} \leq K_{i P_{S}}^{\max }
\end{aligned}
$$

\section{GRAVITATIONAL SEARCH ALGORITHM}

GSA is a physics-inspired optimization method as it is derived and takes derivation and the main features of heuristics from Newton's laws of gravity. It depends on the gravity and mass interactions [29-36].

Based on Newtonian theory, three masses are assigned to a body, which describe its quite different properties; inertial mass $\left(M_{I}\right)$, passive gravitational mass $\left(M_{P}\right)$, and active gravitational mass $\left(M_{A}\right)$ [29-31].

The mass $M_{I}$ is the quantity presented in Newton's second law, which is a measure of a body's inertia. It is a measure of body's resistance to change in motion when a force is applied on the body, i.e., the body opposes that change through its inertial mass. The larger $M_{I}$, the harder it is to accelerate for a given strength of force. $M_{P}$ is a measure of body's reaction to a gravitational field, i.e., it measures a body's response to being placed in a gravitational field, which implies that if $M_{P}$ is placed at some point that has gravitational potential, then it will experience a force on it. $M_{A}$ is a measure of body's source strength for producing a gravitational field by itself [29-32].

Newton's law of gravity indicates that the force between two particles is directly proportional to the product of their masses and inversely proportional to the square of the distance between them, which can be written as [29]:

$$
F=G M_{1} M_{2} / R^{2}
$$

where $\mathrm{F}$ is the magnitude of the gravitational force, $\mathrm{G}$ is the gravitational constant, $M_{1}$ and $M_{2}$ are the masses of the first and second particles, respectively, and ${ }_{R}$ is the distance between them.

Newton's second law indicates that a particle's acceleration $(a)$ depends on the force applied to the particle and the inertial mass $\left(M_{I}\right)$ of the particle, which is expressed as:

$$
a=F / M_{I}
$$


As in the case of physics where performance of objects (particles) is measured by their masses, the agents in this method are attracted to each other based on gravitational force, and their tendency is towards heavier masses, and the heavy masses move in a manner much slower than the lighter ones, and this represents the exploitation behavior.

The GSA algorithm depends on the fact that every mass (agent) has four specifications: position, inertial mass, active gravitational mass, and passive gravitational mass. The algorithm updates gravitational and inertia masses with the help of heavy masses and finds the optimum. This artificial world of masses obeys Newton's law of gravity and motion.

To present the GSA algorithm, consider a system with $N$ agents (masses). The position of the ith agent is defined by [29]:

$$
X_{i}=\left(x_{i}^{1} \ldots x_{i}^{d} \ldots x_{i}^{n}\right) ; i=1,2, \ldots, N
$$

where $x_{i}^{d}$ is the position of ith agent in the dth dimension. The force acting on mass $i$ from mass $j$ at a specific time $t$, is defined as follows [29]:

$$
F_{i j}^{d}=G(t) \frac{M_{P i}(t) M_{A j}(t)}{R_{i j}(t)+\varepsilon}\left(x_{j}^{d}(t)-x_{j}^{d}(t)\right)
$$

where $M_{P i}(t)$ is the passive gravitational mass of agent $i, M_{A j}(t)$ is the active gravitational mass of agent $j, G(t)$ is the gravitational constant at time $t, \varepsilon$ is a small constant, and $R_{i j}(t)$ is the Euclidian distance between two agents $i$ and $j[29]$ :

$$
R_{i j}(t)=\left\|X_{i}(t), X_{j}(t)\right\|
$$

The total force that acts on agent $i$ in a dimension $d$ is a randomly weighted sum of the dth components of the forces exerted by other agents, which is expressed as [29]:

$$
F_{i}^{d}(t)=\sum_{j=1, j \neq i}^{N} \operatorname{rand}_{j} F_{i j}^{d}(t)
$$

where rand $_{j}$ is a random number in the interval $[0,1]$, which is introduced the equation to give a stochastic characteristic to the algorithm. If $M_{I i}(t)$ is the inertial mass of ith-agent, then by the law of motion, the acceleration in direction $d$ of the agent $i$ at time $t$, is given by [29]:

$$
a_{i}^{d}(t)=F_{i}^{d}(t) / M_{I i}(t)
$$

The next velocity of an agent is considered as a fraction of its current velocity added to its acceleration. Therefore, its position and its velocity could be calculated as follows [29]:

$$
\begin{aligned}
& v_{i}^{d}(t+1)=r_{i} \times v_{i}^{d}(t)+a_{i}^{d}(t) \\
& x_{i}^{d}(t+1)=x_{i}^{d}(t)+v_{i}^{d}(t+1)
\end{aligned}
$$

where $r_{i}$ is a uniform random variable in the interval $[0,1]$, which is employed in the equation to give a randomized characteristic to the search. The gravitational constant $G$ is a function of the initial value ( $\left.G_{O}\right)$ and time $(t)$, i.e., it is initialized at the start and will be decreased as time passes to control the search accuracy. This constant is expressed as [29]: 


$$
G(t)=G\left(G_{O}, t\right)=G_{O} e^{-(\alpha / T) t}
$$

where $\alpha$ is a constant specified by a user, $t$ is current iteration and $T$ is the total number of iterations.

Fitness evaluation is used in this algorithm to calculate gravitational and inertia masses. A more efficient agent has a heavier mass, which indicates that better agents have higher attractions with slower walks. The values of gravitational and inertia masses, which are assumed equal, are calculated using the map of fitness. The gravitational and inertial masses are updated by the following Equations [29]:

$$
\begin{aligned}
& M_{i}(t)=m_{i}(t) / \sum_{j=1}^{N} m_{j}(t) \\
& m_{i}(t)=\left(F_{i}(t)-W(t)\right) /(B(t)-W(t)) \\
& M_{A i}=M_{P i}=M_{I i}=M_{i} ; i=1,2, \ldots, N
\end{aligned}
$$

where $F_{i}(t)$ represents the fitness value of the agent $i$ at time ${ }_{t}$. For a minimization problem, $W(t)$ and $B(t)$ are defined as follows [29]:

$$
\begin{gathered}
B(t)=\min _{j \in\{1, \ldots N\}} F_{j}(t) \\
W(t)=\max _{j \in\{1, \ldots N\}} F_{j}(t)
\end{gathered}
$$

For a maximization problem, $W(t)$ and $B(t)$ are defined as follows [29]:

$$
\begin{gathered}
B(t)=\max _{j \in\{1, \ldots m\}} F_{j}(t) \\
W(t)=\min _{j \in\{1, \ldots, m\}} F_{j}(t)
\end{gathered}
$$

Equation (25) can be modified by reducing the number of agents with lapse of time to perform a good compromise between exploration and exploitation, where only a set of agents with bigger mass apply their forces to the others. Let $K_{B}$ is the set of the first $K$ agents with the best fitness values and biggest masses, (25) can be written as [29]:

$$
F_{i}^{d}(t)=\sum_{j \in K_{b}, j \neq i}^{N} \operatorname{rand}_{j} F_{i j}^{d}(t)
$$

The function $K_{b}$ is a function of time, which has an initial value of $K_{O}$ at the beginning and decreases as time passes, which implies that all agents apply the force at the beginning, and as time passes $K_{b}$ is decreased linearly. Finally, just one agent with the best fitness values and biggest masses apply force to the others.

\section{SIMULATION RESULTS}

This section presents the simulation results of the DFIG-based WECS using the GSA-based coordinated optimal tuning of PI controllers. Per-unit system parameters are summarized in Table 1. In order 
to indicate the effectiveness of the GSA to tune the parameters of PI controllers, the results will be compared with the results obtained using GA and PSO as shown Table 2. The GA and PSO are selected in the paper for comparisons as they are becoming very common for solving the optimization problems in different disciplines, essentially in the design of the controllers because of being robust in finding an optimal solution and capable to attain a near-optimal solution close to a global minimum.

Table 1. Parameters of the Simulated System

\begin{tabular}{lcll}
\hline $\begin{array}{l}\text { Stator windings resistance } \\
\text { Rotor windings resistance }\end{array}$ & $r_{S}$ & 0.05 & [p.u.] \\
Stator magnetizing inductance & $\boldsymbol{L}_{r}^{\prime}$ & 0.02 & [p.u.] \\
Rotor leakage inductance & 5.00 & [p.u.] \\
Stator leakage inductance & $L_{l r}^{\prime}$ & 0.10 & [p.u.] \\
Compliance coefficient of the shaft & $L_{l s}$ & 0.10 & [p.u.] \\
Inertia of the turbine & $K_{S h}$ & $0.40 \quad$ [p.u./rad] \\
Inertia of the generator & $H_{\tau}$ & $2.50 \quad$ [sec] \\
& $H_{g}$ & $0.50 \quad$ [sec] \\
\hline
\end{tabular}

Two disturbances are discussed in this paper to show the advantages of using the GSA to tune the PI controller over the other algorithms (GA and PSO). Two performance indices are used to compare between the results. The first one is the objective function (ITAE) and the second one is the settling time for 5\% criterion. The comparisons between the three algorithms are listed in Table 2 and Table 3.

Table 2. Optimal Controller Parameters of GSA, GA, and PSO

\begin{tabular}{cccrrrr}
\hline & \multicolumn{3}{c}{ Fault Disturbance } & \multicolumn{3}{c}{ Reference Speed Disturbance } \\
& GSA & \multicolumn{1}{c}{ GA } & PSO & \multicolumn{1}{c}{ GSA } & \multicolumn{1}{c}{ GA } & \multicolumn{1}{c}{ PSO } \\
\hline$I T A E$ & 0.10585 & 0.28642 & 0.61399 & 1.3265 & 1.38187 & 4.63480 \\
$K_{p \omega}$ & 20.00 & 16.881 & 19.146 & 20.000 & 18.954 & 17.629 \\
& 00 & 35 & 40 & 0 & 94 & 59 \\
$K_{i \omega}$ & 20.00 & 16.384 & 14.289 & 20.000 & 19.036 & 19.027 \\
& 00 & 74 & 63 & 0 & 54 & 92 \\
$K_{p Q}$ & 0.659 & 0.5154 & 0.4850 & 10.131 & 0.0826 & 0.8635 \\
& 10 & 7 & 1 & 7 & 3 & 0 \\
$K_{i Q}$ & 0.050 & 3.9751 & 17.598 & 20.000 & 3.7749 & 6.4840 \\
& 00 & 7 & 22 & 0 & 6 & 3 \\
$K_{p P s}$ & 0.050 & & 0.2964 & 0.0500 & 16.396 & 9.2915 \\
& 00 & 0.1587 & 6 & & 43 & 5 \\
& & 1 & & & & \\
$K_{i P_{s}}$ & 0.641 & 3.1956 & 14.761 & 15.920 & 14.143 & 18.090 \\
& 30 & 2 & 53 & 4 & 75 & 68 \\
\hline
\end{tabular}

Table 3. Calculated Settling time [in seconds]

\begin{tabular}{ccccccc}
\hline & \multicolumn{3}{c}{ Fault Disturbance } & \multicolumn{3}{c}{ Reference Speed Disturbance } \\
& GSA & GA & PSO & GSA & GA & PSO \\
\hline$v_{q r}^{\prime}$ & 0.82 & 1.19 & 1.38 & 2.40 & 2.71 & 2.82 \\
$v_{d r}^{\prime}$ & 0.10 & 0.23 & 0.85 & 1.56 & 1.79 & 1.85 \\
$\omega_{m}$ & 0.04 & 0.06 & 0.11 & 1.04 & 1.42 & 1.54 \\
$P_{s}$ & 0.83 & 0.96 & 1.13 & 2.34 & 2.6 & 2.68 \\
$Q_{s}$ & 0.22 & 0.29 & 0.94 & 0.47 & 0.72 & 0.72 \\
\hline
\end{tabular}

By solving the optimization problem using GSA, GA and PSO, the optimal controller parameters of the system under study are obtained and summarized in Table 2. As can be seen, the values of ITAE 
associated with the GSA-based optimal controllers are better than those obtained using the GA-based and PSO-based optimal controllers. This fact will be reflected in the following response subsections, Figures and Tables. Only five variables $\left(v_{q r}^{\prime}, v_{d r}^{\prime}, P_{s}, Q_{s}\right.$ and $\left.\omega_{m}\right)$ are presented in this paper while the response of the other variables can be estimated from the presented results.

\subsection{Three-phase to Ground Fault}

Three-phase to ground fault was applied after the system reaches to the steady state $(t=10 \mathrm{~s})$ and cleared after $30 \mathrm{~ms}$. From Table 2, 60\% and $80 \%$ reduction of ITAE is achieved using GSA relative to GA and PSO, respectively. Figure 3 and Table 3 show that $v_{d r}^{\prime}$ and $v_{q r}^{\prime}$ can reach the new steady state much faster when GSA is adopted. Figure 4 and Table 3 manifest that using GSA helps the rotor speed to damp in $40 \mathrm{~ms}$ which is two thirds of the time required when GA is used and about one third of the settling time needed when PSO is used. Figure 5 and Figure 6 illustrates the advantages of using GSA to compensate $P_{S}$ and $Q_{S}$, respectively. The settling time for the active power is at least $13 \mathrm{~ms}$ faster when GSA is considered. For the reactive power, GSA reduced the settling time by about $25 \%$ at least.
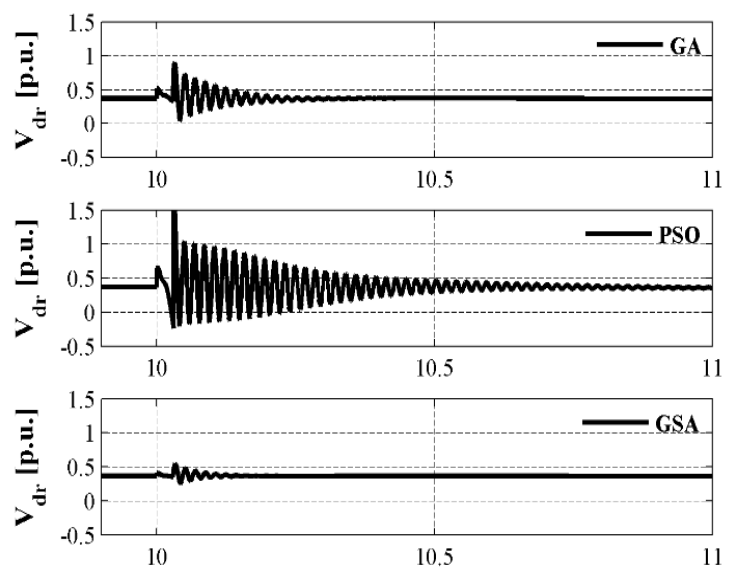

(a)
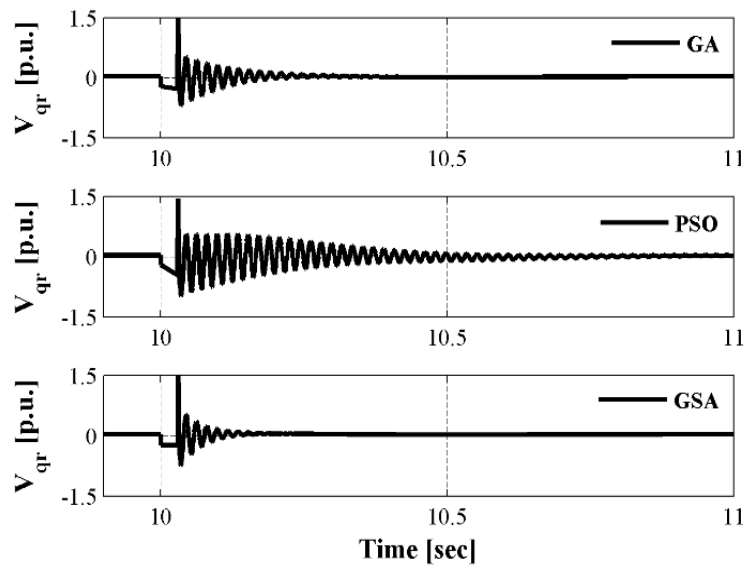

(b)

Figure 3. The rotor voltages when three-phase to ground fault is applied using GA, PSO and GSA: (a) $v_{d r}^{\prime}$ and (b) $v_{q r}^{\prime}$
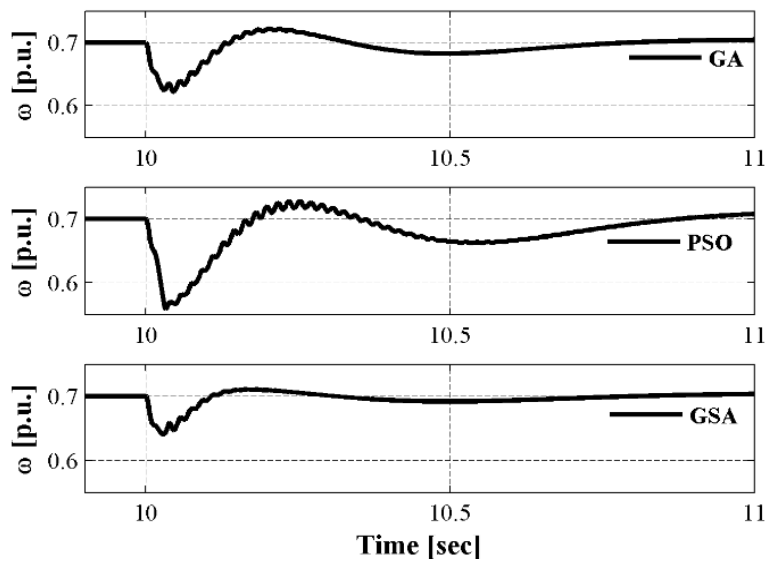

Figure 4. The rotor angular speed when three-phase to ground fault is applied using GA, PSO and GSA 

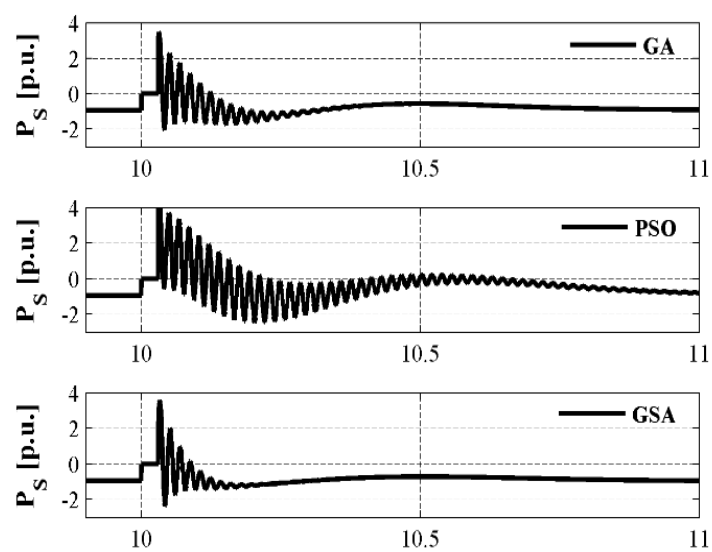

(a)
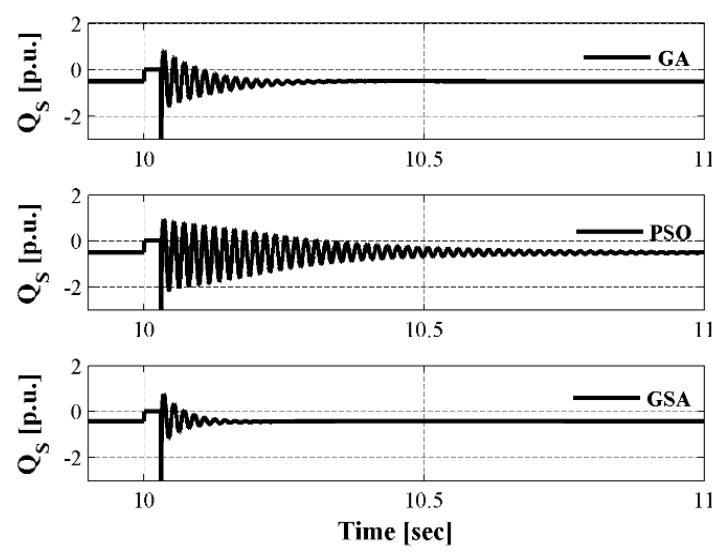

(b)

Figure 5. The stator active and reactive power when three-phase to ground fault is applied using GA, PSO and GSA: (a) $\mathrm{P}_{\mathrm{s}}$ and (b) $\mathrm{Q}_{\mathrm{s}}$

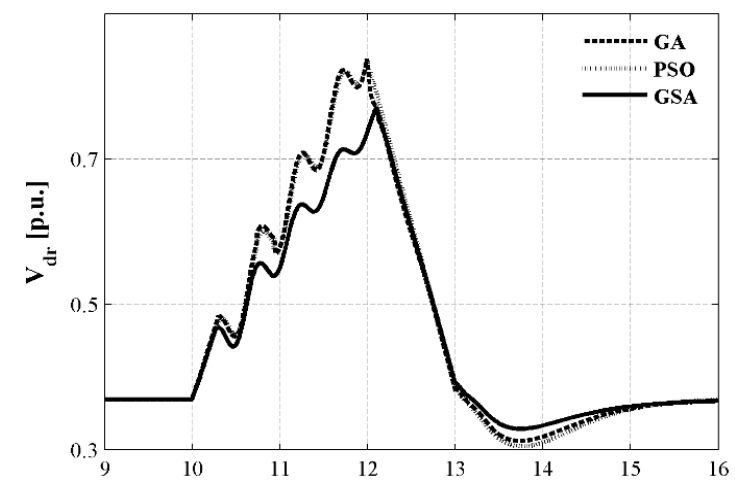

(a)

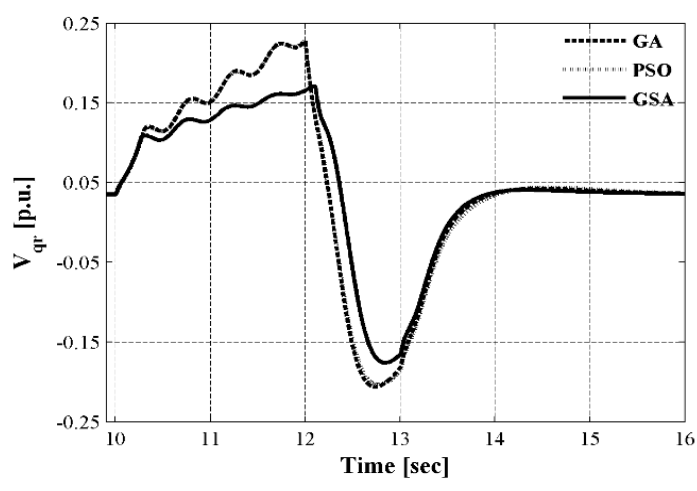

(b)

Figure 6. The rotor voltages when the reference speed is changed using GA, PSO and GSA: (a) $v_{d r}$ (b) $v_{q r}$

\subsection{Variable Reference Speed}

In this disturbance and as shown in Figure 6, the reference speed $\omega_{m, \text { ref }}$ was initially set to 0.7 p.u., after that, the speed is reduced to 0.35 p.u. in one second. Next, the reference speed stays constant for one second and finally increases linearly to the initial reference value.

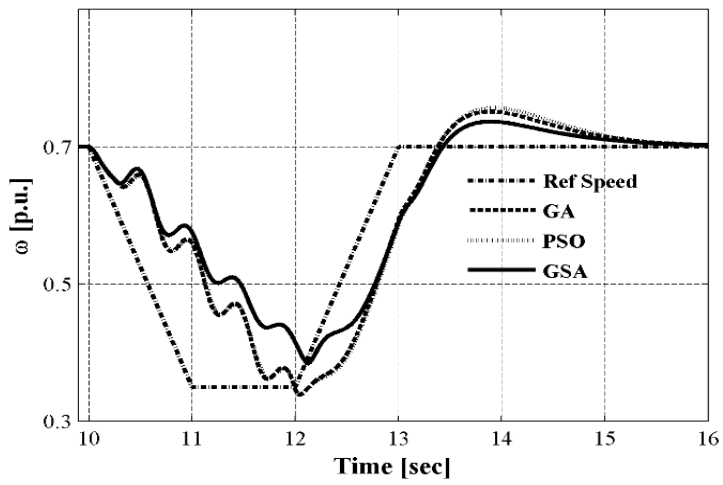

Figure 7. The rotor speed with changing the reference speed using GA, PSO and GSA 
From Table 2, a smaller ITAE is associated with the GSA as seen in Figure 6. The settling time of the output variables listed in Table 3 is damped faster by at least $0.38 \mathrm{~s}$ when GSA is used. The rotor voltages shown in Figure 7 clarifies that both GA and PSO give almost a similar response while GSA can reduce the maximum over shoot during the acceleration or the deceleration periods.

The stator active and reactive power shown in Figure 8 clearly show the advantage of using GSA to damp the response much faster. Using GSA, the system requires $0.47 \mathrm{~s}$ to damp the reactive power while it takes $150 \%$ of this time when GA or PSO are adopted.

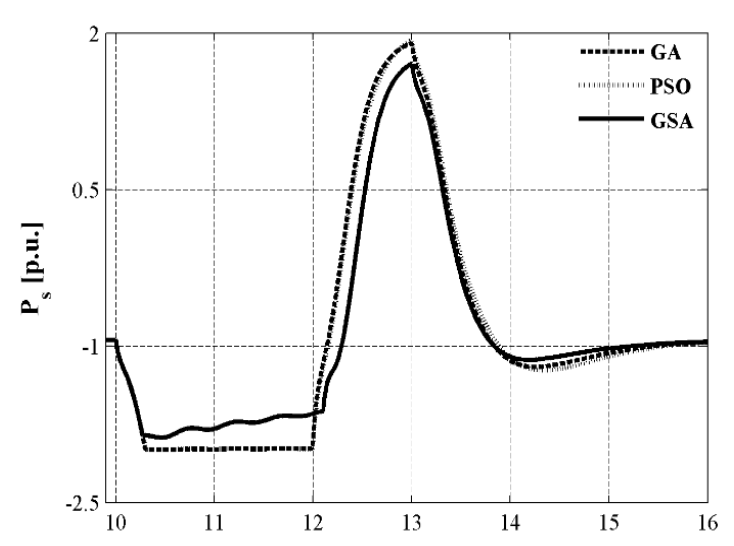

(a)

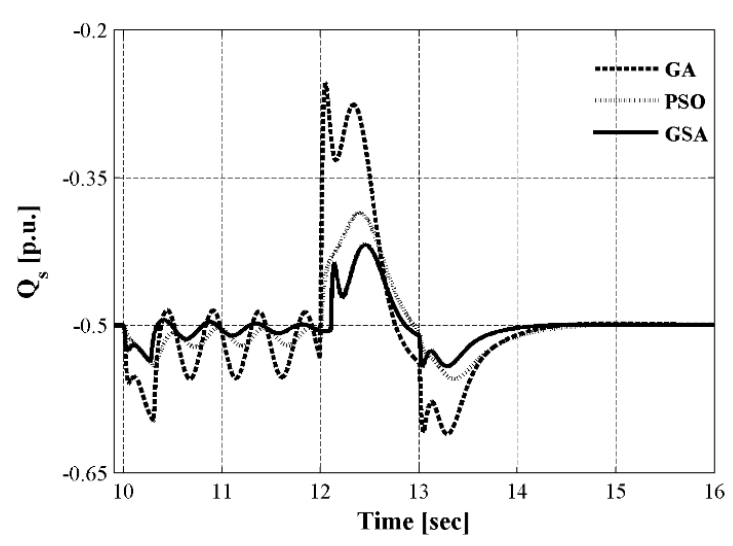

(b)

Figure 8 . The stator active and reactive power under variable reference speed using GA, PSO and GSA: (a) $P_{s}$ (b) $Q_{s}$

\section{CONCLUSIONS}

In this paper, GSA is used to design optimal controllers for improving the transient response of a nonlinear DFIG-based WECS. The designed optimal controllers are tested under different common types of disturbances. The results are compared to the results obtained using the two well-recognized global optimization algorithms, which are GA and PSO, to show the effectiveness of using GSA to attain a global optimal solution of the design problem under study. A time-weighted absolute error (ITAE) is used in the objective function to stabilize the system and increase its damping when subjected to different types of disturbances. The comparative simulations confirm the fruitiness of the GSA and its effectiveness to damp the system faster than the GA and the PSO. Mathematically, the considered measured performance indices (ITAE and the settling time) show clearly the advantages of applying GSA over the other two algorithms for different disturbances.

\section{REFERENCES}

[1] Boulahia A, Nabti K, Benalla H."Direct Power Control for AC/DC/ACConverters in Doubly Fed Induction Generators Based Wind Turbine", International Journal of Electrical and Computer Engineering (IJECE). 2012; $2(3) ; 425-432$

[2] Anju M, Rajasekaran R."Power System Stability Enhancement and Improvement of LVRT Capability of a DFIG Based Wind Power System by Using SMES and SFCL", International Journal of Electrical and Computer Engineering (IJECE). 2013; 3(5); 618-628.

[3] Hamane B, Benghanemm M, Bouzid A, Belabbes A, Bouhamida M, Draou A. "Control for Variable Speed Wind Turbine Driving a Doubly Fed Induction Generator using Fuzzy-PI Control”. Energy Procedia. 2012; 18; 476-485.

[4] Zamanifar M, Fani B, Golshan M, Karshenas H. "Dynamic modeling and optimal control of DFIG wind energy systems using DFT and NSGA-II". Electric Power Systems Research; 2014; 108; 50-58.

[5] Chakravarty P, Venayagamoorthy G. "Development of optimal controllers for a DFIG based wind farm in a smart grid under variable wind speed conditions". 2011 IEEE International Electric Machines \& Drives Conference (IEMDC). 2011. Niagara Falls, ON, Canada

[6] Yang L, Yang G.Y, Xu Z, Dong Z.Y, Wong K.P, Ma X. "Optimal controller design of a doubly-fed induction generator wind turbine system for small signal stability enhancement”, IET Generation, Transmission \& Distribution 2010; 4 (1); 579-597. 
[7] Suryoatmojo H, Zakariya A.M.B, Anam S, Musthofa A, Robandi I. "Optimal controller for doubly fed induction generator (DFIG) using Differential Evolutionary Algorithm (DE)," in Intelligent Technology and Its Applications (ISITIA); 2015; 159-164

[8] Vieira J.P.A, Nunes M.V.A, Bezerra U.H, Nascimento A.C. "Designing optimal controllers for DFIGs using a genetic algorithm", IET Generation, Transmission\& Distribution. 2009; 3 (1); 472-484.

[9] Sitharthan R, Geethanjali M. "An adaptive Elman neural network with C-PSO learning algorithm based pitch angle controller for DFIG based WECS". Journal of Vibration and Control, 2016; 23(5), pp.716-730.

[10] Hoseinpoor A, Gardoon Piraei A, Asgar M, Mohammadzaki M. "DFIG WIND TURBINES CONTROLL BY PSO ALGORITHM", Journal of Fundamental and Applied Sciences. 2016; 8 (2); 3638-3646.

[11] Mukhopadhyay B, Mandal R. "Application of Artificial Intelligence-Based Techniques in Controlling the STATCOM Used for Compensation for Voltage Dips in DFIG-Based Grid-Connected Wind Power System'. Lecture Notes in Electrical Engineering, 2017; pp.177-189.

[12] Bharti, Om Prakash, R. K. Saket, and S. K. Nagar. "Controller Design of DFIG Based Wind Turbine by Using Evolutionary Soft Computational Techniques." Engineering, Technology \& Applied Science Research 7.3 (2017): pp-1732.

[13] Panda and M. Tripathy, "Optimal power flow solution of wind integrated power system using modified bacteria foraging algorithm”, International Journal of Electrical Power \& Energy Systems. 2014; 54; 306-314.

[14] Venu Madhav G, Obulesu Y. P. "A New Hybrid Artificial Neural Network Based Control of Doubly Fed Induction Generator”, International Journal of Electrical and Computer Engineering (IJECE). 2015; 5 (3); 379-390.

[15] Dahiya P, Sharma V, Sharma R. "Optimal Generation Control of Interconnected Power System Including DFIGBased Wind Turbine", IETE Journal of Research. 2015; 61 (3). 285-299

[16] Roy R, Jadhav H. "Optimal power flow solution of power system incorporating stochastic wind power using Gbest guided artificial bee colony algorithm", International Journal of Electrical Power \& Energy Systems. 2015; 64 (1); $562-578$

[17] Kahla S, Soufi Y, Sedraoui M, Bechouat M. "On-Off control based particle swarm optimization for maximum power point tracking of wind turbine equipped by DFIG connected to the grid", International journal of hydrogen energy. 2015; 40 (39); 13749-13758.

[18] Vepa R. "Nonlinear, optimal control of a wind turbine generator", IEEE Transactions on Energy Conversion, 2011; 26 (2); 468-478.

[19] Yun-tao S, Qi K, Yan-jiao H, Yang Z, De-hui S, Zheng-xi L. "A Hybrid optimal control structure of DFIG Wind Energy Convert System," in Intelligent Control and Automation (WCICA), 2014 11th World Congress on , vol., no., pp.4982-4987, June 29 2014-July 42014

[20] Vrionis T, Koutiva X, Vovos N. "A Genetic Algorithm-Based Low Voltage Ride-Through Control Strategy for Grid Connected Doubly Fed Induction Wind Generators”, IEEE Trans. Power Syst., 2014; 29 (3); 1325-1334.

[21] Xiang D, Ran L, Tavner P, Yang S. "Control of a Doubly Fed Induction Generator in a Wind Turbine During Grid Fault Ride-Through", IEEE Transactions on Energy Conversion, 2006; 21 (3); 652-662.

[22] Barros L, Mota W, da Silva J, Barros C. "An optimal control strategy for DFIG, " 2010 IEEE International Conference. march 2010; $1727-1732$.

[23] Sheikhan M, Shahnazi R, Nooshad Yousefi A. "An optimal fuzzy PI controller to capture the maximum power for variable-speed wind turbines”, Neural Comput \& Applic. 2012; 23 (5); 1359-1368.

[24] Ruiz-Cruz R, Sanchez E, Ornelas-Tellez F, Loukianov A, Harley R. "Particle Swarm Optimization for DiscreteTime Inverse Optimal Control of a Doubly Fed Induction Generator," IEEE Trans. on Cybernetics, 2013; 43 (6); $1-9$.

[25] Feng W, Xiao-Ping Z, Ping J, Sterling M. "Decentralized Nonlinear Control of Wind Turbine With Doubly Fed Induction Generator", IEEE Trans. Power Syst.2008; 23 (2); 613-621.

[26] Qiao W. Vanayagamorthy G.K, Harley R.G. "Design of optimal PI controllers for doubly fed induction generators driven by wind turbines using particle swarm optimization", Intl. Joint Conf. on Neural Networks 2016, pp.1982-1987

[27] Vieira J, Bezerra U, Nunes M, Nascimento A. "Designing optimal controllers for doubly fed induction generators using a genetic algorithm", IET Generation, Transmission \& Distribution, 2009; 3 (5); 472-484.

[28] Jeba, V.E.; Ravichandran, S.; Devi, R.P.K., "Optimal control of grid connected variable speed wind energy conversion system," in Energy Efficient Technologies for Sustainability (ICEETS); 393-399, 10-12 April 2013

[29] Rashedi E, Nezamabadi-pour H, Saryazdi S. "GSA: A Gravitational Search Algorithm”, Information Sciences, Vol. 179, No. 13, pp. 2232-2248, 2009.

[30] Rashedi E, Nezamabadi-pour H, Saryazdi S. "BGSA: binary gravitational search algorithm", Natural Computing, 2009; 9 (3);727-745.

[31] Balachandar S, Kannan K. "Newton's Law of Gravity-Based Search Algorithms," Indian Journal of Science and Technology. 2013; 6 (2); 2013.

[32] Ibrahim T.N.T, et al." "A Brief Analysis of Gravitational Search Algorithm (GSA) Publication from 2009 to May 2013, " Int. Conf. on Recent treads in Engineering \& Technology (ICRET'2014), Feb 13-14, 2014, Batam, Indonesia.

[33] Ajami and A. J. Shendi, "Application of UPFC Tuned Based on Gravitational Search Algorithm to Damping of Low Frequency Oscillations," Int. J. of Advanced Research in Computer Science and Software Engineering. 2013; 3 (7); 2013.

[34] Tosun S, Oztürk A, Ertay M. M, Yalçın M.A, Zengin A.“An Approach For Designing Passive Power Filters For Industrial Power Systems By Using Gravitational Search Algorithm, ” Tehnički vjesnik. 2015; 22 (2); 343-349. 
[35] Duman S, Guvenc U, Sonmez Y, Yorukeren N. "Optimal power flow using gravitational search algorithm," Energy Conversion and Management, 2012; 59; 86-95.

[36] Boulahia, Adel M, Hocine B. "Predictive Power Control of Grid and Rotor Side converters in Doubly Fed Induction Generators Based Wind Turbine," International Journal of Electrical and Computer Engineering (IJECE). 2013; 3 (3); 287-293.

\section{BIOGRAPHIES OF AUTHORS}

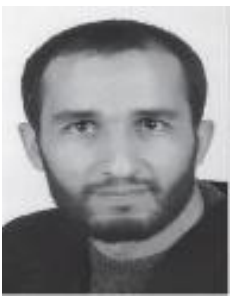

Saher Albatran received the B.Sc. degree in electric power engineering from Yarmouk University, Irbid, Jordan, in 2005. He received his M.Sc. degree in electric power and control engineering from the Jordan University of Science and Technology, Irbid, in 2008 and his Ph.D. degree in electrical engineering from Mississippi State University, Mississippi State, MS, USA in 2013. He is currently an Assistant Professor with the Department of Electrical Engineering, Jordan University of Science and Technology, Irbid, Jordan. His research interests include integration distributed generation, optimization of power system and motor drives.

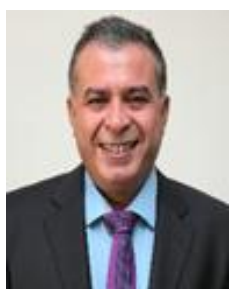

Muwaffaq I. Alomoush was born in Jordan in 1967. He received the B.Sc. (1990) and the M.Sc. (1994) degrees in electrical engineering from the Jordan University of Science and Technology (JUST), Irbid, Jordan, and the Ph.D. degree (1999) in electrical engineering from Illinois Institute of Technology (IIT), Chicago, U.S. He is currently a professor of the Electrical Power Engineering Department, Hijjawi Faculty for Engineering Technology, Yarmouk University, Irbid, Jordan. His areas of interest are power system control, power system restructuring, economic operation of power system, FACTS applications in restructured systems, and optimization of power system.

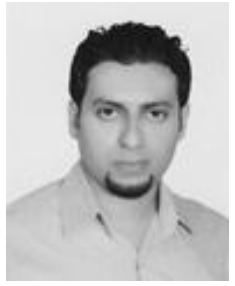

Ahmed M. Koran received the B.Sc. (2004) in Electrical Power Engineering from Yarmouk University, Irbid, Jordan. He received the M.Sc. (2007) and the Ph.D. (2013) degrees in Electrical Engineering from Illinois Institute of Technology (IIT), Chicago, U.S. and Virginia Polytechnic Institute and State University (VT), Blacksburg, USA, respectively. He is currently an assistant professor and the chairman of the Electrical Power Engineering Department, Hijjawi Faculty for Engineering Technology, Yarmouk University, Irbid, Jordan. His research interests include the modeling, design, and optimization of Power Electronics systems for renewable energy applications. 